\title{
Poučevanje in učenje verjetnosti v osnovni in srednji šoli
}

\author{
Daniel Doz \\ Državni znanstveni licej »France Prešeren« s slovenskim učnim jezikom \\ doz_daniel@yahoo.it
}

Darjo Felda

Univerza na Primorskem

darjo.felda@pef.upr.si

\author{
Mara Cotič \\ Univerza na Primorskem \\ mara.cotic@pef.upr.si
}

Verjetnostni račun je veja matematike, ki se ukvarja s kvantificiranjem nedoločenosti. Čeprav je verjetnost prisotna v številnih vsakodnevnih situacijah in je temelj različnih znanosti, je poučevanje verjetnosti v osnovnih in srednjih šolah še vedno podpovprečne kakovosti. Raziskave kažejo, da imajo odrasli in otroci napačne presoje, ko se ukvarjajo s situacijami, povezanimi z verjetnostjo. V prispevku predstavimo razloge za poučevanje verjetnosti v osnovni in srednji šoli ter načela poučevanja verjetnosti na stopnji osnovnošolskega in srednješolskega izobraževanja. Predstavimo ravni poučevanja verjetnosti v osnovni in srednji šoli ter teoretični model podkrepimo s primeri, ki jih lahko učitelji uporabljajo pri poučevanju verjetnosti.

Ključne besede: verjetnost, matematika, osnovna šola, srednja šola, verjetnostna pismenost

\section{Uvod}

Verjetnostni račun je del matematike, katerega cilj je kvantificiranje nedoločenosti z namenom, da se posameznik bolje odloča. Verjetnost uporabljamo vsakodnevno v različnih situacijah: za vremenske napovedi, pri loteriji in drugih igrah (Amir in Williams 1999; Sharma 2015; Candelario-Aplaon 2017; Fast 1997). Prav zaradi uporabnosti verjetnostnega računa $v$ različnih vedah in disciplinah, kot so fizika, ekonomija, medicina, ekologija in znanost nasploh (Sharma 2015; Candelario-Aplaon 2017; Batanero in Díaz 2012; Paul in Hlanganipai 2014), se je verjetnost uvedlo v program skoraj vsake šole na svetu (Kapadia in Borovcnik 1991; Batanero idr. 2016; Batanero in Díaz 2012).

$\mathrm{V}$ zadnjem desetletju je postalo poučevanje verjetnosti še posebej pomembno (Metz 2010): v literaturi se pojavlja vedno več raziskav, ki pouče- 
vanje verjetnosti analizirajo $z$ različnih zornih kotov (npr. statističnega, praktičnega, teoretičnega) in na različnih stopnjah izobraževanja (npr. osnovna in srednja šola, univerza). Pojavilo se je veliko zanimanje za t. i. »verjetnostno pismenost « (Gal 2005; 2009): gre za zmožnost interpretiranja in kritične presoje informacij, povezanih z verjetnostjo in s slučajnostjo, pri čemer je kontekst, $v$ katerem se pojavi informacija, ključnega pomena. $S$ tem sta povezani zmožnost razumevanja pojmov in jezika, ki se jih v verjetnostnem računu uporablja, ter pravilna uporaba verjetnostnih argumentov (Borovcnik 2016).

Poučevanje verjetnostnega računa preko praktičnih primerov in situacij, $s$ katerimi se učenec srečuje vsakodnevno, je učinkovitejše od zgolj teoretične obravnave verjetnosti (Cai idr. 2020; Konold 1994; Sheikh 2019), saj praktična uporaba in aplikacije učeče se dodatno motivirajo (Gürbüz in Birgin 2012; Halpern 1987; Zetterqvist 2017).

Čeprav se je verjetnostni račun uveljavil v različnih učnih programih na različnih stopnjah šolanja, sta Mezhennaya in Pugachev (2018) poudarila potrebo, da se razvije nove učne metode za poučevanje verjetnostni in statistike, saj se pri odraslih še vedno pojavljajo različne napake pri verjetnostnem sklepanju in ocenjevanju verjetnostnih dogodkov. Ljudje verjetnost dogodkov ocenjujejo hevristično, kar privede do napak v ocenjevanju verjetnosti in različnih napačnih predstav (Tversky in Kahneman 1974; 1983; Kahneman in Tversky 1972; Kahneman 2003). Kahneman in Tversky (1982) predstavljata primer, ko so morali odrasli presoditi, kateri izmed dogodkov pri šestkratnem metu (poštenega) kovanca je najverjetnejši (C - cifra, $M$ - mož): (1) CMCMMC, (2) CCCMMM ali (3) CCCCMC. Znano je, da je pri poštenem kovancu vsak izid enako verjeten in da ima Bernoullijevo zaporedje šestih neodvisnih metov kovanca enako verjetnost. Anketiranci so se odločali za prvo možnost, saj je po njihovem mnenju predstavljala bolj »slučajno « razporeditev izidov in bila verjetnejša kot druga in tretja. Za tretjo možnost so sodelujoči trdili, da ne predstavlja dogodka pri šestkratnem metu poštenega kovanca.

Fischbein in Gazit (1984) trdita, da imajo učitelji matematike veliko odgovornost, da pri učencih prepoznajo nepravilne hevristike in jih posledično odpravljajo. Verjameta namreč, da se napačna razmišljanja na področju verjetnostnega računa nadaljujejo tudi takrat, ko se učečim se predstavi pravilno, formalno teorijo verjetnostnega računa.

Gürbüz in Birgin (2012) opažata, da je poučevanje verjetnosti kot take samo po sebi problematično, kljub temu da je poznavanje verjetnostnega računa ključnega pomena $v$ vsakdanjem življenju, še posebej $v$ fazi odločanja. Po njunem mnenju je pomanjkljivo ali celo napačno poučevanje verjetnosti posledica različnih napačnih predstav in hevristik, ki jih imamo ljudje, ko se 
ukvarjamo z verjetnostjo: napake v logičnem mišljenju onemogočajo učenje verjetnosti.

Ker je verjetnost za posameznika pomembna, da se bolje odloča, ko se srečuje s slučajnimi dogodki (Batanero idr. 2016), in se obenem izogne napakam, ki so tipične za verjetnostno razmišljanje, je verjetnost nujno poučevati že $v$ osnovni šoli (Taylor 2011). Ob zaključku osnovnošolskega izobraževanja naj bi namreč učenec že dosegel določeno raven matematične pismenosti, ki obsega matematično razmišljanje ter uporabo matematičnih konceptov in postopkov, s katerimi lahko opisujemo, razlagamo in predvidevamo pojave. $\checkmark$ prispevku predstavimo razloge za poučevanje verjetnostnega računa ter didaktična priporočila za poučevanje verjetnostni v osnovni in srednji šoli.

\section{Izhodišča za poučevanje verjetnosti}

Glede matematičnih vsebin, ki bi jih bilo potrebno učiti v šoli, se je uveljavilo mnenje, da morajo biti učeči se v stiku z vsebinami, ki jih bodo nato uporabljali v vsakodnevnem življenju (Fast 1997). To mnenje sicer dopolnjuje še potreba, da so težave, s katerimi se učenci srečujejo, življenjske in ne zgolj konkretne (Carraher in Schliemann 2002). To pomeni, da se morajo učenci srečevati $z$ avtentičnimi težavami uporabe verjetnosti v realnem življenju, vendar morajo biti te težave take, da učencu prispevajo ne zgolj praktično znanje, temveč tudi nove metode za kritično presojo sveta, ki ga obdaja (Toh in Queenie 2020).

Poučevanje verjetnostnega računa $v$ državah $O E C D$, pa tudi drugod, je dodatno spodbudila mednarodna raziskava PISA (Programme for International Studet Assessment) (Ottaviani 2011). Raziskava PISA meri znanje 15-letnih učencev na štirih matematičnih področjih (PISA 2018a; 2018b):

- količina (števila in velikost);

- prostor in oblika (geometrija);

- spremembe in odnosi (funkcije in relacije);

- negotovost (slučajnost).

V raziskavi PISA (2018b, 26) je zapisano:

V znanosti, tehnologiji in vsakodnevnem življenju se srečujemo s spremembami in negotovostmi, ki so vezane na le-te. Gre za pojave, ki so srce teorije verjetnostni in statistike. Kategorija negotovosti in analize podatkov vključuje prepoznavanje pomena sprememb v realnem življenju, kvantificiranje teh sprememb in določanje negotovosti in napakv inferenčnih postopkih. Vključuje tudi izoblikovanje, interpretacijo 
Negotovost v vsakodnevnem življenju: prepoznavati, kvantificirati, določati

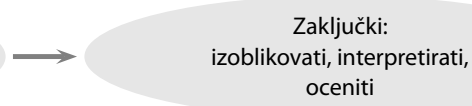

Slika 1 Model uporabe, učenja in poučevanja verjetnosti

in ocenjevanje zaključkov, ki nastanejo na podlagi pojavov, kjer je prisotna negotovost. [...] Predvidevanja v ekonomiji, volitvah in napovedovanju vremena vse vključujejo merjenje sprememb in negotovosti.

Iz zgornjega zapisa razberemo, da je verjetnost področje, s katerim se človek srečuje vsakodnevno, od učencev pa se zahteva, da pomen verjetnostnega računa prepoznajo tudi v vsakdanjem življenju.

Besede v poročilu PISA $(2018 \mathrm{~b}, 26)$ razvijemo v model (slika 1) uporabe verjetnosti tako $v$ didaktične kot praktične primere. Učenci najprej prepoznajo spremembe in negotovosti realnih situacij, nato kvantificirajo in nazadnje določijo njihovo negotovost. Na podlagi informacij, ki jih dobijo, bi učenci zmogli izoblikovati zaključke, jih pravilno interpretirati in oceniti.

Čeprav so praktična in uporabna narava verjetnostnega računa (Kapadia in Borovcnik 1991; Batanero idr. 2016, 1; Batanero in Díaz 2012) ter vključevanje verjetnosti v mednarodnih preizkusih matematičnega znanja (Ottaviani 2011) spodbudili poučevanje verjetnostnega računa $v$ osnovnih in srednjih šolah po celem svetu, se to poučevanje še vedno naslanja na poučevanje formul, procedur in reševanja problemov (Batanero in Diaz 2012; Gal 2005). To posledično pomeni, da učenci ne pridobijo sposobnosti verjetnostnega razmišljanja ter ne znajo pravilno oceniti verjetnosti enostavnih slučajnih dogodkov.

To dejstvo potrjujejo številne raziskave, ki so se večinoma začele leta 1972 (Tversky in Kahneman 1974; 1983; Kahneman in Tversky 1972; Kahneman 2003), nadaljujejo pa se še danes. $V$ literaturi najdemo zapise, da se $v$ zvezi $z$ ocenjevanjem in računanjem verjetnosti pojavljajo različne napake in neprave predstave. Sodelujoči v raziskavah so enako verjetne dogodke ocenjevali subjektivno, hevristično. Hevristike so miselni procesi, ki nas z intuicijo privedejo do (relativno hitrega) odgovora. Hevristike lahko pridobimo z izkušnjami, težko pa se jim izognemo. Khazanov in Prado (2010) sta opravila eksperiment, kjer je bila eksperimentalna skupina deležna dodatnega izobraževanja na področju verjetnosti, kontrolna skupina pa ne. Opazila sta, da se $v$ obeh skupinah pojavljajo nepravilne predstave in napake pri ocenjevanju verjetnosti določenih dogodkov, kot so izidi pri metu poštenega kovanca. Podobne rezultate sta dobila tudi Ang in Shahrillova (2014). 
Poleg težav, ki jih imajo učenci z ocenjevanjem verjetnosti zaradi hevristik, so druge raziskave pokazale, da se učenci pri reševanju nalog iz verjetnosti srečujejo tudi s težavami z branjem in razumevanjem besedila ter s postopki, ki jih je potrebno uporabiti. Triliana in Asih (2019) navajata primer, ko je skupina učencev pravilno prebrala besedilo naloge, vendar ga ni popolnoma razumela oz. je imela težave pri razumevanju določenih pojmov in besed. Druga skupina učencev je razumela, kaj od njih naloga zahteva, vendar se ni mogla odločiti, kateri matematični postopek ali zaporedje postopkov je bilo potrebno uporabiti pri reševanju problema. Avtorja zaključujeta, da bi morali učitelji večjo pozornost nameniti poučevanju verjetnosti. Misel podpirata tudi Gürbüz in Birgin (2012), ki verjameta, da je večina napak v verjetnostnem mišljenju pri učencih pravzaprav posledica prisotnosti različnih hevristik in nepravih predstav.

Vzorec, ki sta ga Triliana in Asih (2019) upoštevala, je sicer majhen, saj je šlo za raziskavo s petimi dijaki (starosti 13-14 let). Nekoliko večji vzorec (29 študentov) so uporabljali Astutijeva, Anggraeni in Setyawan (2020), ki so pri sodelujočih opredelili štiri kategorije napak: (1) nerazumevanje problema; (2) postopkovne napake; (3) nerazumevanje Bayesovega izreka; (4) napake $v$ računanju verjetnosti dogodka. Najpogostejša napaka, ki se je pojavila $v$ njihovem eksperimentu, je nepravilna interpretacija oz. nerazumevanje problema. Avtorja zaključujeta z nasvetom, da bi morali učitelji dodatno spodbujati učenje verjetnosti, da do tovrstnih napak ne bi prihajalo. Batanerova idr. (2016) opažajo, da se mnogi učenci učijo formul na pamet in ne razumejo vprašanj. Pomanjkanje matematičnega predznanja učencev in uporaba nepravilnih učnih metod in instrumentov s strani učiteljev predstavljata dodatno težavo (Conley idr. 2020; Danışman in Tanişli 2018).

Predhodno opisani primeri nakazujejo, da imajo učenci večje težave pri reševanju nalog iz verjetnostnega računa. Kot primer si oglejmo nalogo D12 iz italijanskega vsedržavnega preizkusa znanja matematike INVALSI za dijake 2. razreda višje srednje šole (14- in 15-letni dijaki) iz leta 2014 (slika 2). Nalogo sestavljajo štiri podvprašanja, a. in b. sta iz statistike, c. in d. pa iz verjetnosti. $\checkmark$ preglednici 1 je predstavljen odstotek pravilnih in nepravilnih odgovorov, ki smo jih dobili na uradni spletni strani Gestinv (2021). Na vprašanje je odgovarjalo 36.932 dijakov. Na prvi dve vprašanji je pravilno odgovorilo okrog $83 \%$ dijakov, na tretje $32 \%$, na četrto pa le $24,1 \%$ dijakov. Dijaki so spretni pri reševanju problemov iz statistike, manj pa pri reševanju nalog, ki zahtevajo uporabo verjetnostnega računa.

Oglejmo si še nalogo D11 (slika 3) iz leta 2013, na katero je odgovorilo 38.533 dijakov (Gestlnv 2021). Nalogo sestavljata dva dela, oba s področja verjetno- 
Slika 2

Naloga D12 z

italijanskega

nacionalnega preizkusa

INVALSI 2014
D12. Na vzorcu 1500 žensk starosti 25 do 55 let so za mesečno revijo posvečeno zdravju izvedli anketo, da bi spoznali mnenja bralk o reviji. Anketa je dala naslednje rezultate:

\begin{tabular}{|l|c|c|}
\hline & Zaposlene & Brezposelne \\
\hline Pozitivno mnenje & 450 & 276 \\
\hline Negativno mnenje & 367 & 407 \\
\hline
\end{tabular}

a. Koliko anketirank je izrazilo pozitivno mnenje? Odgovor:

b. Koliko anketirank je brezposelnih? Odgovor:

c. Kolika je verjetnost, da je slučajno izbrana anketiranka izrazila negativno mnenje? Odgovor: ..............

d. Če slučajno izbereš anketiranko med tistimi, ki so oddale pozitivno mnenje, kolikšna je verjetnost, da je zaposlena?

Odgovor: ...............

Preglednica 1 Deleži pravilnih in nepravilnih odgovorov na vprašanje D12 (v odstotkih)

\begin{tabular}{lrrrr}
\hline Vprašanje & Nepravilni & Pravilni & Ni odgovorilo & Drugo \\
\hline D12_a & 12,1 & 83,0 & 4,7 & 0,2 \\
D12_b & 11,6 & 83,3 & 5,0 & 0,1 \\
D12_c & 38,2 & 32,0 & 29,2 & 0,6 \\
D12_d & 45,4 & 24,1 & 29,9 & 0,6 \\
\hline
\end{tabular}

Opombe Povzeto po Gestlnv (2021).

stnega računa. Odgovor na vprašanje D11_a dobimo z računanjem verjetnosti nasprotnega dogodka. Na to vprašanje je pravilno odgovorilo 69,0\% dijakov (28,3\% nepravilnih odgovorov; $2,7 \%$ jih ni odgovorilo). Pravilni odgovor je A. Zanimivo je, da je $16,7 \%$ vseh dijakov odgovorilo $D$, kar je enako verjetnosti, da dobimo neoporečno palico, ne pa pokvarjeno. Možno je, da so slabo prebrali besedilo naloge. Odgovor na vprašanje D11_b dobimo z računanjem verjetnosti dveh neodvisnih dogodkov kot zmnožek posameznih verjetnosti (pravilni odgovor je B). Pravilnih je bilo le $26,3 \%$ odgovorov (67,3\% napačnih; 6,4\% jih ni odgovorilo). Analiza odgovorov pokaže, da je $33,5 \%$ vseh dijakov odgovorilo A: dijaki so torej upoštevali največjo verjetnost med obema. 14,6\% dijakov je odgovorilo C, kjer so sešteli verjetnosti, da ne dobimo neoporečne palice, 19,2\% pa jih je verjetnosti, da ne dobimo neoporečne palice, zmnožilo in odgovorilo D.

S primeroma iz italijanskega nacionalnega preizkusa znanja smo želeli pokazati, da se pri reševanju nalog iz verjetnostnega računa pojavljajo različne napake in da večina dijakov ni sposobna reševati takih nalog. Rezultati kažejo, da se več dijakov srečuje z večjimi težavami pri reševanju bolj ali manj enostavnih nalog iz verjetnosti. 


\section{Slika 3}

Naloga D11 z italijanskega nacionalnega preizkusa INVALSI 2014

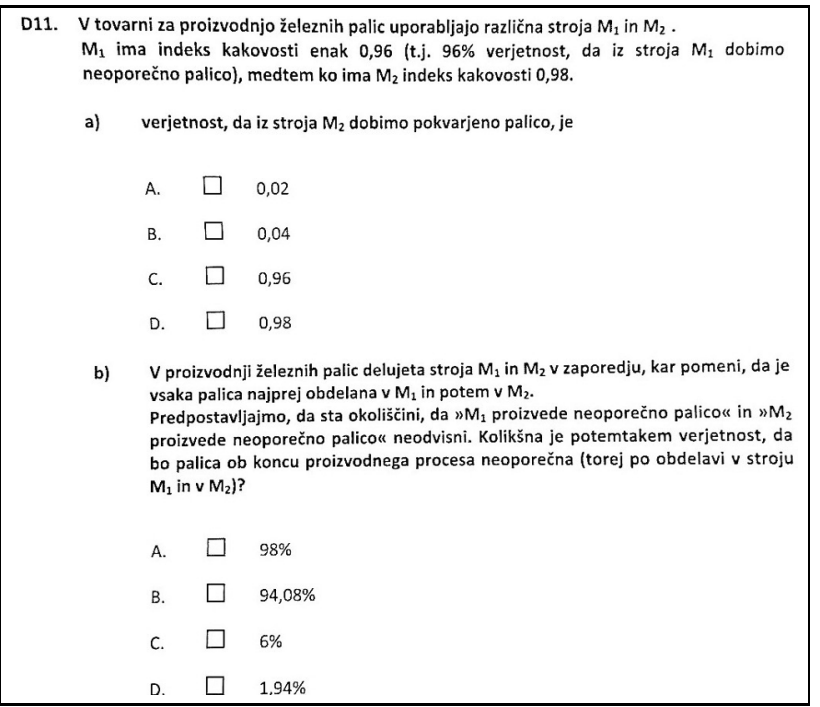

Sprašujemo se, zakaj imajo učenci nižje dosežke pri verjetnostnem računu v primerjavi z ostalimi področji matematike (Ottaviani, Mignani in Ricci 2005). Razumevanje verjetnostnega računa zahteva nedeterministični način mišljenja, ki ga učenci in dijaki manj razvijajo od determinističnega (Pristovnik, Peer in Hodnik Čadež 2011; Cotič, Felda in Kozel 2009). Razen verjetnosti ostala matematična področja temeljijo na determinističnem načinu mišljenja, to je na načelu dvovalentne logike, kjer imamo samo dve možni vrednosti: pravilno ali nepravilno (Cotič, Felda in Kozel 2009). V verjetnostnem računu uporabljamo multivalentno logiko (Clermont 2015; 2020), tj. tisto, kjer je več možnih vrednosti. Ponazorimo s primerom: $v$ verjetnosti je nek dogodek lahko slučajen (torej ne zgolj gotov ali nemogoč), tj. njegova verjetnost zavzame poljubno vrednost med o in 1. Ker dvovalentna logika v verjetnosti odpove, imajo mnogi učenci in odrasli večje težave pri dojemanju verjetnostnih pojmov (Cotič, Felda in Kozel 2009).

Če želimo, da človek pravilno deluje $v$ družbi, mora kot posameznik sprejeti dejstvo, da v naravi obstaja tudi slučajnost, nedeterminizem; obenem mora razviti in usvojiti strategije mišljenja, ki mu bodo pomagale sprejeti odločitve v slučajnih dogodkih v vsakodnevnem in profesionalnem življenju (Batanero idr. 2016; Wang in $X u$ 2016). Nedeterministične sheme razmišljanja so prisotne $v$ različnih vedah in znanostih, kot so npr. genetika, biologija, medicina, ekonomija in politika.

$\checkmark$ matematiki se srečujemo s protiintuitivnimi pojmi $v$ višjih stopnjah ab- 
straktnosti (Batanero in Sanchez 2005), ki jih učenci osnovne in srednje šole navadno niso deležni. $V$ verjetnostnem računu se od učenca zahteva način mišljenja, ki je tuj logičnemu in determinističnemu, zato imajo učenci več težav tudi z osnovnimi pojmi (Borovcnik in Peard 1996). Ko sta Borovcnik in Kapadia (2009) raziskovala razloge, zakaj imajo učenci toliko težav pri razumevanju nekaterih vsebin verjetnostnega računa, sta ugotovila, da jih večina naloge rešuje zgolj z intuicijo in pri tem ne uporablja logike. Razhajanje med logiko in intuicijo predstavlja težavo za učence (Koparan in Yilmaz 2015), ki potrebujejo šolsko pripravo kot podlago za razumevanje pojmov iz verjetnostnega računa. Poučevanje verjetnostnega računa naj bi se začelo že $v$ osnovni šoli (Cotič, Felda in Kozel 2009). Že Piaget je ugotovil, da se zametki pojma možnost pojavijo $v$ drugi fazi otrokovega razvoja (Nikiforidou 2018; Aslan in Wilensky 2016), ko se razvijajo logične in aritmetične operacije. V tej fazi otrok verjetnostno mišljenje razvije preko fenomenizma, pasivne indukcije in egocentrizma. Nadalje je Fischbein podprl teorijo, da bi bilo potrebno že otrokom predstaviti kompleksno intuitivno osnovo verjetnostnega mišljenja, ter nasprotoval Piagetovi teoriji in zagovarjal, da so 6-7 let stari otroci že sposobni razumeti pojem slučaj (Nikiforidou 2018). Čeprav sta si mnenji Fischbeina in Piageta nasprotujoči, poudarjamo, da je Piaget prisotnost verjetnostnega mišljenja poskušal utemeljevati z zornega kota razvojne psihologije, medtem ko se je Fischbein istega problema loteval s pedagoškega zornega kota.

Kasneje so Jones in sodelavci $(1997 ; 1999)$ z eksperimenti pokazali, da so pri otrocih prisotne štiri ravni verjetnostnega mišljenja: (1) subjektivno mišljenje, ko otrok intuitivno oceni verjetnost dogodka na podlagi svojih osebnih preferenc; (2) mišljenje med subjektivnim in naivnim kvantitativnim, ko otrok poskuša kvantificirati verjetnosti; (3) informalno kvantitativno mišljenje, ko otrok uporablja določene strategije za naštevanje ugodnih dogodkov danega poskusa; (4) numerično mišljenje, ko otrok uporablja števila za merjenje verjetnosti. Iz teh eksperimentov torej sledi, da so otroci že sposobni verjetnostnega mišljenja, kar utemeljuje možnost uvedbe učenja osnovnih pojmov verjetnosti že $v$ osnovni šoli. Kasnejši eksperimenti so pokazali, da so štiriletni (Nikiforidou 2019) oz. petletni (Girotto idr. 2016) otroci sposobni inferenčnega razmišljanja in ocenjevanja verjetnosti, iz česar sklepamo, da je mogoče verjetnostni račun predstaviti tudi v vrtcu. Podobne zaključke so eksperimentalno dobili tudi Cotičeva, Felda in Kozel (2009), ki zaključujejo, da je mogoče verjetnostni račun uvesti v vrtcih in prvem razredu osnovne šole. Hodnik Čadeževa in Škrbčeva (2011) sta kasneje opravili raziskavo, s katero zaključujeta, da so nekateri 4 do 5 let stari otroci sposobni dojemati nekatere 
osnovne pojme, vezane na verjetnost dogodkov. Povzemimo torej razloge za poučevanje verjetnosti:

1. Otroci so kognitivno sposobni razumeti osnovne pojme verjetnosti že na predšolski stopnji, gotovo pa $v$ prvih razredih osnovne šole. Potrebno je spodbuditi njihovo intuicijo in jim predstaviti osnove verjetnostnega mišljenja ter enostavne primere računanja verjetnosti.

2. Verjetnostno mišljenje se bistveno razlikuje od tistega na drugih matematičnih področjih; gre za nedeterministično mišljenje, ki je nujno za funkcioniranje posameznika $v$ današnji družbi.

3. Elementi verjetnostnega računa in nedeterminističnega mišljenja so prisotni v vsakdanjem življenju, in sicer ko se mora posameznik soočati s situacijo naključja in negotovosti. Poleg tega gre za bistveni element mnogih znanstvenih in družboslovnih ved.

4. Pri učencih, dijakih, študentih in odraslih se v verjetnostnem razmišljanju kažejo mnoge napake, ki so vezane na hevristike in napačne predstave. Cilj poučevanja matematike je čim prej odpraviti napačne predstave in učencu nuditi pravilne interpretacije verjetnosti dogodkov.

\section{Poučevanje verjetnosti}

V prejšnjem razdelku smo predstavili razloge za poučevanje verjetnosti. Izsledki različnih raziskav (predstavljenih $v$ prejšnjem razdelku) kažejo na to, da je poznavanje verjetnosti ključnega pomena $v$ vsakdanjem življenju, žal pa se pri mnogih učencih in odraslih pojavljajo različne napake pri reševanju bolj ali manj enostavnih nalog, ki zahtevajo verjetnostno mišljenje. Obvladanje vsebin iz verjetnosti je ključnega pomena v vsakdanjem življenju, zato je potrebno verjetnost pravilno učiti v osnovni in kasneje srednji šoli ter na univerzi (Batanero in Díaz 2012). V tem razdelku bomo predstavili nekaj didaktičnih priporočil za poučevanje verjetnosti v osnovni in srednji šoli. Podrobno predstavimo ravni poučevanja verjetnosti in na podlagi teh še nekaj primerov poučevanja.

\section{Didaktična priporočila}

Učenje in poučevanje verjetnosti v osnovni šoli ni formalno in eksplicitno, kot je v srednji šoli. V osnovni šoli učenci sistematično pridobivajo izkušnje, ki jih bodo naknadno poglobili in formalizirali v srednji šoli (Cotič 2013). V osnovni šoli ne govorimo o formalni definiciji verjetnosti, naj bo to klasična ali statistična definicija, in niti o formalnem računanju verjetnosti dogodkov, temveč učitelji učence pripravijo na kasnejšo matematično analizo slučajnih 
dogodkov na podlagi intuicije in igre. Učenci naj bi s smiselno stopnjevanimi vajami in dejavnostmi pridobili izkušnje z negotovimi oz. slučajnimi dogodki, sproti pa spoznavali pojme, načela in kompetence predvidevanja. Na primer: učenci razumejo, da pri stotih metih kovanca ni pričakovati, da bi cifra padla natanko 50-krat, čeprav je verjetnost, da pri posameznem metu pade cifra, enaka $50 \%$ oz. 1/2. Statistična verjetnost, to je verjetnost, ki se jo učenci učijo preko praktičnih primerov in iger, učencem pomaga, da razumejo osnovna načela, ki se jih poslužujemo pri analizi negotovih dogodkov (Andrew 2009). Učenci $v$ naslednjih fazah učenja verjetnosti ne potrebujejo več toliko izvedb poskusov, saj verjetnosti ocenjujejo abstraktneje (Andrew 2009). Pri tem razvijejo tudi nedeterministično mišljenje, in sicer preko dejavnosti (Cotič 2013):

1. opisa tistega, kar je za učenca mogoče oz. nemogoče (prim. Hodnik Čadež in Škrbec 2011);

2. razlikovanja med gotovimi, slučajnimi in nemogočimi dogodki (prim. Hodnik Čadež in Škrbec 2011);

3. smiselne in dosledne uporabe izrazov, kot so mogoče, nemogoče, je možno, je slučajno, je enako verjetno, je manj verjetno, je verjetneje ipd., v sklopu praktičnih dejavnosti, kot so npr. met kocke, žreb kroglic ali met kovanca (prim. Tsakiridou in Vavyla 2015);

4. primerjanja verjetnosti raznih dogodkov med seboj;

5. postavljanja smiselnih hipotez pri predvidevanju izidov preprostih iger na srečo, pri čemer trditve nato podprejo z izkušnjami;

6. zapisovanja izidov slučajnih dogodkov (npr. pri metu kocke, kovanca ali žreba kroglic) v preglednice in s histogrami.

Opisane dejavnosti vključuje tudi učni načrt za matematiko v osnovni šoli (Ministrstvo za šolstvo in šport 2011). Poudarja se pomen, ki ga ima pridobivanje izkušenj o verjetnosti in ocenjevanja le-te s sklepanjem in z utemeljevanjem iz življenjskih situacij. Učenci naj bi torej izvajali poskuse, kot so meti kocke, žebljičkov ali kovancev, da bi opazovali izbrane dogodke ter zapisali izide in na podlagi teh napovedovali verjetnost dogodkov.

Empirizem, izvajanje poskusov in igra imajo v zgodnji fazi učenja verjetnosti pomembno vlogo. Učenci se torej preko iger in večkratnih ponovitev poskusov naučijo predvidevanja: razumevanje statistične verjetnosti določenih izidov pripomore k zavedanju pomena verjetnosti. Andrew (2009) predstavi naslednje pozitivne plati izvajanja poskusov $v$ učenju in poučevanju verjetnosti: 
1. izvajanje poskusov učencem pomaga, da razumejo razliko med možnimi in ugodnimi izidi;

2. večkratno izvajanje istega poskusa lahko učencem pomaga, da razumejo, koliko so dogodki verjetni;

3. izvajanje poskusov učencem pomaga razumeti teoretične rezultate, ki jih dobijo s formulami.

V kasnejših fazah, tj. v srednji šoli, imajo dijaki že izoblikovano idejo verjetnostnega računa, saj so se $v$ osnovni šoli srečali z empiričnimi raziskavami $v$ zvezi z verjetnostjo nekaterih dogodkov. Dijaki naj bi nato, s pomočjo znanja kombinatorike, znali določiti verjetnost slučajnih dogodkov, poznali osnovne pojme verjetnostnega računa in znali izmeriti ter interpretirati empirične verjetnosti. Poleg tega bi morali tudi poznati pojem matematična verjetnost ter jo znati izračunati in rezultate interpretirati (Strokovni svet Republike Slovenije za splošno izobraževanje 2007). Skratka, dijaki (Strokovni svet Republike Slovenije za splošno izobraževanje 2007; Ministrstvo za šolstvo in šport 2008):

1. poznajo osnovne pojme verjetnostnega računa (npr. vzorčni prostor, dogodek, poskus, izid, nezdružljivi dogodki, neodvisni dogodki);

2. znajo zapisati dogodke in računati z njimi;

3. razlikujejo med subjektivno, empirično in matematično (klasično) definicijo verjetnosti ter znajo povezovati te pojme med sabo;

4. znajo uporabljati klasično definicijo verjetnosti;

5. na podlagi danih verjetnosti dogodkov znajo računati verjetnosti drugih;

6. rešujejo naloge s pomočjo formul.

Dijaki se $z$ verjetnostjo začnejo ukvarjati preko analize verjetnosti dogodkov, s katerimi se srečujejo $v$ vsakdanjem življenju; $v$ tej fazi ima intuicija, ki so si jo izoblikovali v osnovni šoli, še pomembno vlogo. Na konkretnih primerih dijaki spoznajo empirične verjetnosti (npr. preko relativnih frekvenc in primerjanja le-teh s teoretično izračunano verjetnostjo). Pomembno vlogo imata kritična presoja rezultatov in interpretacija le-teh (glej tudi predstavljeni model na sliki 1) pa tudi medpredmetno povezovanje, na primer z biologijo (dedovanje in genetika).

Glede poučevanja verjetnosti na srednji šoli smo iz literature ugotovili, da je problematično, saj imajo dijaki še vedno težave $z$ dojemanjem osnovnih pojmov in računanjem verjetnosti elementarnih dogodkov (Batanero in Sanchez 2005), navadno zaradi težav z razumevanjem kombinatoričnih pojmov 


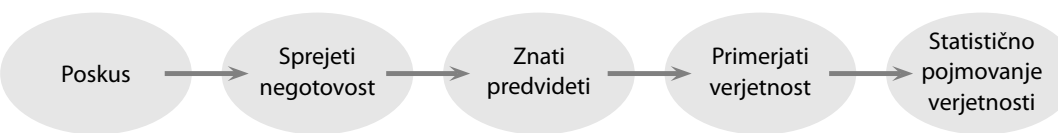

Slika 4 Ravni učenja in poučevanja verjetnosti v osnovni šoli

(Busadee in Laosinchai 2013). V ta namen se je potrebno zavedati oz. si prizadevati za naslednje:

1. dijaki naj bodo v stiku z realnimi podatki, ki bi jim pomagali oceniti razliko med empiričnimi dogodki in verjetnostnimi modeli (Batanero in Sanchez 2005; Batanero, Henry in Parzysz 2005);

2. praktične dejavnosti so dobrodošle, saj dijaki lahko razumejo, kako teoretične modele uporabljati za predvidevanje različnih dogodkov iz vsakdana (Batanero in Sanchez 2005; Busadee in Laosinchai 2013);

3. praktične dejavnosti pripomorejo $\mathrm{k}$ razumevanju pojma verjetnostne porazdelitve, npr. Gaussove (Batanero in Sanchez 2005);

4. pouk verjetnosti učitelj obogati z uporabo tehnologije in grafičnih prikazov, ki dijakom pomagajo razumeti določene situacije - pri tem je koristno, da imajo dijaki stik z realnimi podatki, s čimer razvijejo svoje sposobnosti reševanja problemov (Batanero in Sanchez 2005; AizikovitshUdi in Radakovic 2012), obenem je uporaba računalnika pri pouku verjetnosti smiselna oz. se morajo dijaki soočati z vsakdanjimi in s praktičnimi situacijami (Batanero, Henry in Parzysz 2005);

5. uporaba skic in drugih grafičnih reprezentacij problemov (npr. kombinatorična drevesa, Vennovi diagrami) dijakom pomaga pri reševanju zahtevnejših problemov (Corter in Zahner 2007).

\section{Ravni poučevanja verjetnosti}

Poučevanje verjetnostnega računa v osnovni šoli se bistveno razlikuje od poučevanja v srednji šoli. V osnovni šoli so v ospredju empirizem, raziskovanje, razumevanje verjetnostnih pojmov preko izvajanja poskusov in igre. $V$ srednji šoli pa se verjetnost obravnava s formalnejšega, logično-matematičnega zornega kota, ki vsekakor zahteva intuicijo, ki naj bi jo dijak usvojil v osnovni šoli. Cotičeva (2013) predstavlja model poučevanja verjetnosti na različnih ravneh (slika 4):

1. Poskus: učenje verjetnostni se začne s pojmom poskus, s katerim so povezani koncepti gotovega, slučajnega in nemogočega dogodka. Hodnik Čadeževa in Škrbčeva (2011) predstavita primere gotovih, slučajnih 

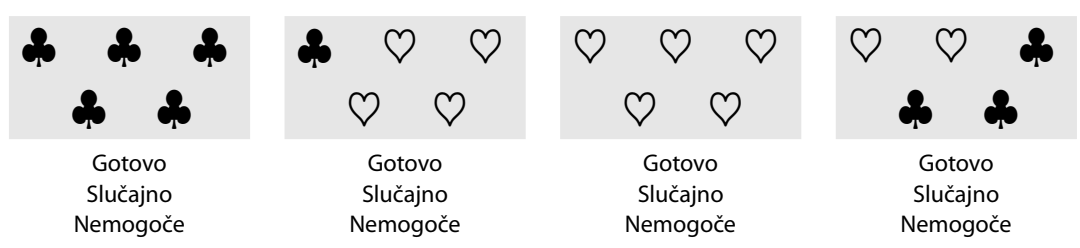

Slika 5 Primer določanja gotovih, slučajnih in nemogočih dogodkov (prirejeno po Hodnik Čadež in Škrbec 2011, 276)

in nemogočih dogodkov (slika 5), ki jih je pravilno rešilo 68,4 \% učencev prvega razreda ter $85,5 \%$ učencev drugega razreda osnovne šole. $V$ nalogi so učenci izbrali, ali je izbor avtomobilčka iz dane množice gotov, slučajen ali nemogoč dogodek.

2. Sprejetinegotovost: prvi korak učenja in poučevanja verjetnosti v osnovni šoli je vodenje učenca, da sprejme negotove situacije brez anksioznosti; gre torej za uvajanje pojma slučajnega dogodka. Že Piaget in Inhelderjeva (2015) sta opazila, da se za otroka nič ne zgodi slučajno, zato mora biti vse hoteno, načrtovano in določeno. Otrok, ki pri igrah na srečo ne zmaga, je prepričan, da je bil prevaran. To pri njem povzroči nelagodje, jezo in jok. Obenem ima subjektivnost pri tem odločilno vlogo: otrok, ki mu je najbolj všeč rdeča barva, bo izjavil, da je gotovo, da se bo ta vedno pojavila (Jones idr. 1999). Prav zato ga je potrebno voditi do spoznanja, da je lahko nek dogodek ne zgolj gotov ali nemogoč, temveč tudi slučajen. To lahko učitelji naredijo postopno, in sicer s pomočjo iger in dejavnosti, ki imajo za cilj otroku pokazati, da se pri igrah na srečo (kot so npr. igra s kocko, žreb kroglic, met kovanca, loterija ipd.) srečujemo z negotovimi situacijami in moramo le-te mirno sprejemati. Navajamo primer: prva dejavnost naj bo met kovanca. Učence se vpraša, katere izide pričakujejo. Da v primeru »napačnega« odgovora ne izpostavljamo posameznih učencev, učence prosimo, da svoje predvidevanje zapišejo na listek in nato listek vstavijo v škatlo. Po metu kovanca bo učitelj prebral predvidevanja. Postopek naj se ponovi nekajkrat. Preko te enostavne dejavnosti učenci lahko razumejo, da bodo nekajkrat »uganili« izid, občasno pa ne. Istočasno učenci spoznajo, da ni nekega privilegiranega izida ter da je subjektivnost $v$ tem primeru neuporabna (npr. »dobimo moža, ker ima lep obraz«). Aktivnost lahko učitelji dodatno nadgradijo s tem, da vsakega učenca prosijo, naj vrže kovanec, da se razblini prepričanje, da je lahko met »nepošten«.

3. Znati predvideti: pojme gotovih, slučajnih in nemogočih dogodkov 
učenci pridobivajo $s$ situacijami, kjer so sami aktivni (Vahey, Enyedy in Gifford 2000; Veloo in Chairhany 2013); v teh situacijah bodo znali predvideti, ali je dogodek gotov, nemogoč ali slučajen. Pri tem je pomembno, da se srečujejo s pojmi »mogoče«, »morda«, »ne vem«, "zagotovo«, »nemogoče« ter jih znajo smiselno uporabljati (prim. Tsakiridou in Vavyla 2015; Brijlall 2014). Situacije naj bodo vsekakor take, da jih lahko ponovimo pod enakimi pogoji (npr. met kocke, met kovanca ipd.), da lahko učenci po večkratnih izkušnjah pridejo do sklepa, npr., »nemogoče je dobiti sedmice« ali »možno je, da vržem štiri«. Obenem zmorejo sprejeti dejstvo, da se predvideni dogodek ni zgodil. Če si, npr., ogledamo zgoraj omenjeni poskus meta kovanca, imajo učenci možnost napovedati izid, nakar svoje predvidevanje preverijo in ugotovijo, da ni nujno, da se je njihova napoved uresničila. Piaget sicer trdi, da otroci v operativno konkretni fazi razvoja ne znajo razlikovati med gotovimi in slučajnimi dogodki ter da imajo težave pri predvidevanju. Namreč, učenci predvidevajo s tem, da se naslanjajo na načeli ponavljanja (tj. »če je bil prej izid mož, bom tudi zdaj dobil moža«) oz. kompenzacije (tj. »če je bil prej izid mož, mora zdaj priti cifra«) (Nikiforidou 2019). S ponavljanjem istega poskusa pod istimi pogoji se učenec prepriča, da napovedi ne morejo biti subjektivne narave.

4. Primerjati verjetnosti: pojem verjetnosti se pri učencih na začetku gradi kot sposobnost obvladovanja slučajnih dogodkov na podlagi izkušenj in izvajanja poskusov. Učenci posledično razumejo, da so nekateri dogodki bolj ali manj verjetni oz. celo enako verjetni: znajo kvalitativno oceniti verjetnost slučajnega dogodka. Pomembno je, da jim predstavimo igre in dejavnosti, v katerih so nekateri dogodki bolj, drugi pa manj verjetni. Npr., druga naloga, ki jo predstavljata Hodnik Čadeževa in Škrbčeva $(2011,276)$ (slika 5), učence sprašuje, ali je verjetneje izvleči avtomobilček $v$ drugem ali četrtem primeru. Učenec lahko do odgovora pride s tem, da isti poskus opravi v enakih pogojih večkrat.

5. Statistično pojmovanje verjetnosti: učenec se nauči uporabe statistične definicije verjetnostni s praktičnimi primeri. Cotičeva (2013) predlaga, da bi učitelj v razred prinesel vrečo s kroglicami različnih barv. Učenci nato preštejejo, koliko je kroglic posamezne barve. Na podlagi števila kroglic posamezne barve morajo nato oceniti, kolikšna je verjetnost, da bo izvlečena kroglica točno določene barve. Nato učenčeva predvidevanja preverimo empirično; učenci izvlečejo posamezne kroglice in zabeležijo izid s pomočjo tabele. Poskus je potrebno ponoviti velikokrat (npr. 100- ali 200-krat). S pomočjo učitelja bodo učenci razumeli, 
Slika 6

Primer uporabe statistične definicije verjetnosti pri metu kovanca

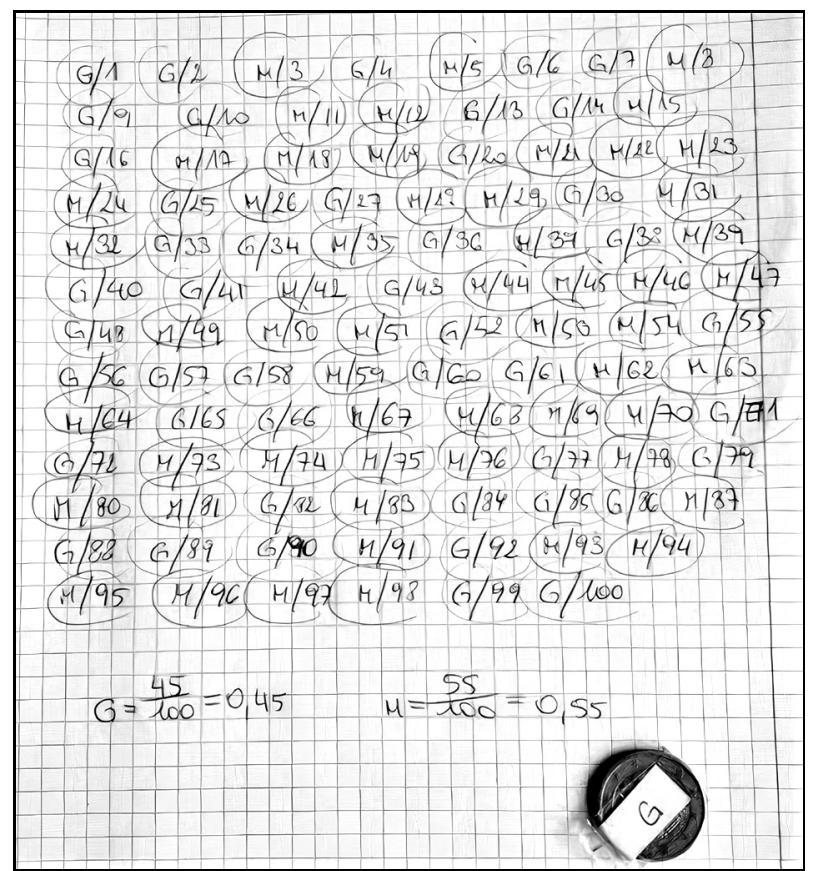

da se $z$ večanjem števila poskusov relativne frekvence bližajo določenemu številu (formalno gre za proces limite, ko se število poskusov veča $\checkmark$ nedogled): to je verjetnost iskanega dogodka. Na sliki 6 predstavimo primer računanja verjetnosti izidov meta poštenega kovanca v tretjem triletju. Učenka (14 let, gimnazija s slovenskim učnim jezikom v Italiji) je na kovanec prilepila oznaki »G« (glava) in »M« (mož). Izide je zapisala v obliki izid/število meta. Nato je obkrožila izide »G« in »M«, jih preštela in delila s številom metov (100).

Statistično pojmovanje verjetnosti (slika 4) predstavlja zadnjo fazo poučevanja verjetnostnega računa $v$ osnovni šoli (Cotič 2013), ki bi se naravno nadaljevala z uporabo klasične definicije verjetnosti. Obenem se dijaki v srednji šoli soočajo z osnovami kombinatorike (Strokovni svet Republike Slovenije za splošno izobraževanje 2007; Ministrstvo za šolstvo in šport 2008), zato je shema ravni, ki jih prehodijo, da bi razumeli klasično in statistično definicijo verjetnosti, kot je prikazano na sliki 7.

1. Kombinatorična situacija: računanje elementarnih verjetnosti lahko izpeljemo iz kombinatoričnih situacij, kar vodi v klasično definicijo ver- 


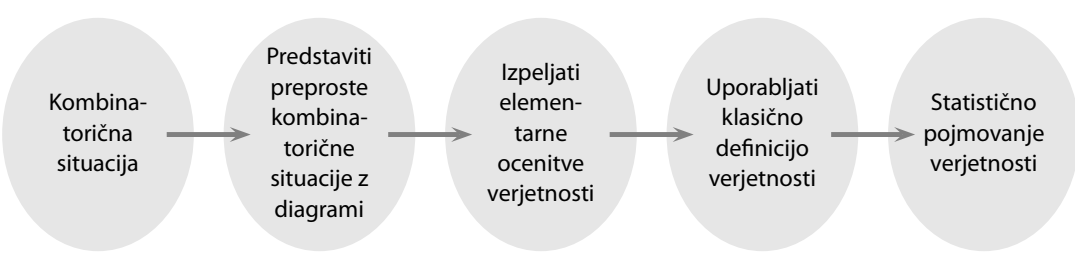

Slika 7 Ravni učenja in poučevanja verjetnosti v srednji šoli (prirejeno in dopolnjeno po Cotič 2013)

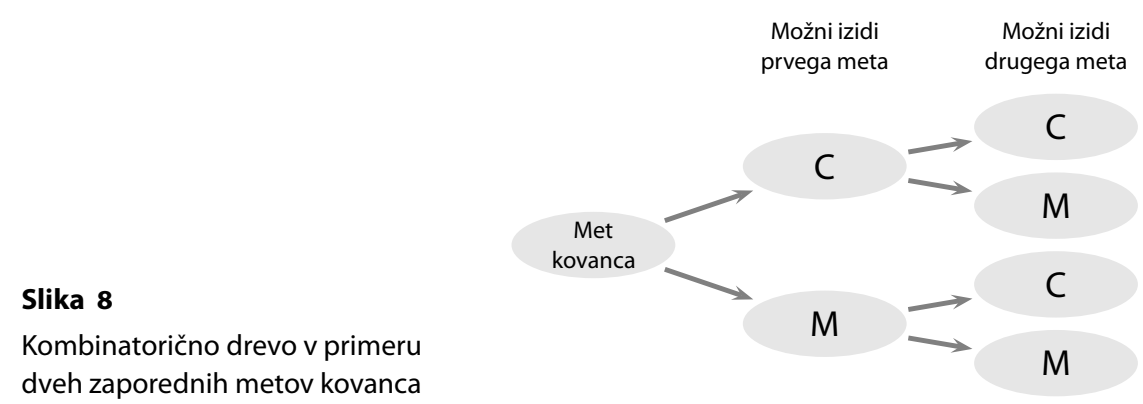

jetnosti. Piaget in Inhelderjeva (2015) sta opazila, da učenci razumejo in rešujejo kombinatorične naloge na ravni formalnih operacij. To pomeni, da so dijaki srednje šole že sposobni uporabljati osnovne kombinatorične pojme za to, da rešijo naloge iz verjetnostnega računa. Npr., izračunajo verjetnost, da $v$ dveh zaporednih metih poštenega kovanca dvakrat dobimo cifro.

2. Predstavitev preprostih kombinatoričnih situacij z diagrami: zgoraj omenjeni problem lahko dijaki rešijo s pomočjo kombinatoričnega drevesa (slika 8). Tako se lahko hitro naučijo metode predstavitve preprostih kombinatoričnih situacij z diagrami; to posledično pomeni, da bodo ob srečevanju s situacijami, ki zahtevajo permutacije ali permutacije s ponavljanjem, zmožni uporabljati isto metodo (Cotič 2013).

Ponazorimo s primerom: Anino geslo na telefonu je sestavljeno iz štirih števk, ki se lahko ponavljajo. Vse možne izide bomo izračunali s pomočjo kombinatoričnega drevesa (slika 9). Iz prikaza učenec razume, da lahko prvo števko izbira izmed desetih možnih števk. Tudi vsako nadaljnjo števko izbiramo izmed desetih možnih števk.

3. Izpeljava elementarnih ocen verjetnosti: s kombinatoričnimi situacijami dijak lažje računa verjetnosti dogodkov, ki jih v osnovni šoli ni mogel določiti na preprost način. $V$ primeru kovanca (slika 8) ugotovi, da je verjetnost, da v dveh zaporednih metih kovanca dobi dve cifri, enaka: 


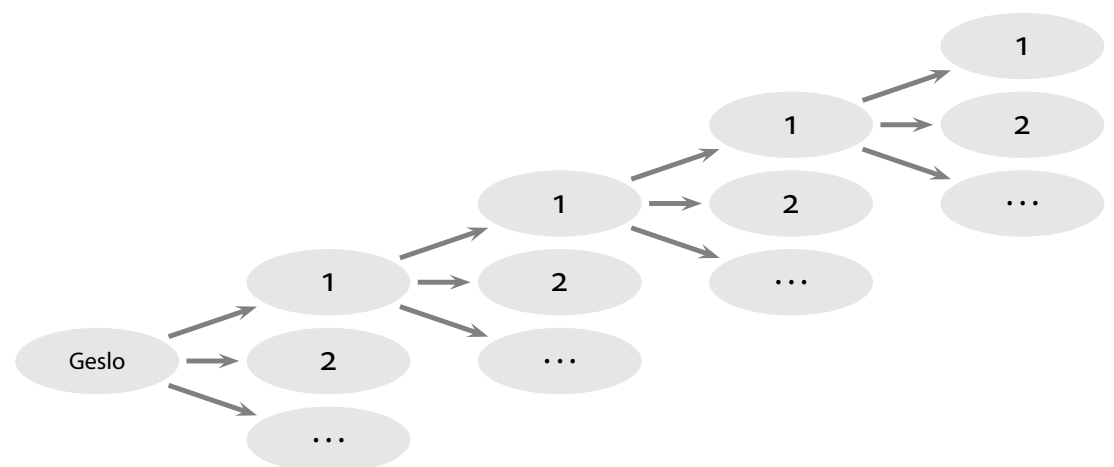

Slika 9 Kombinatorično drevo v primeru iskanja Aninega gesla

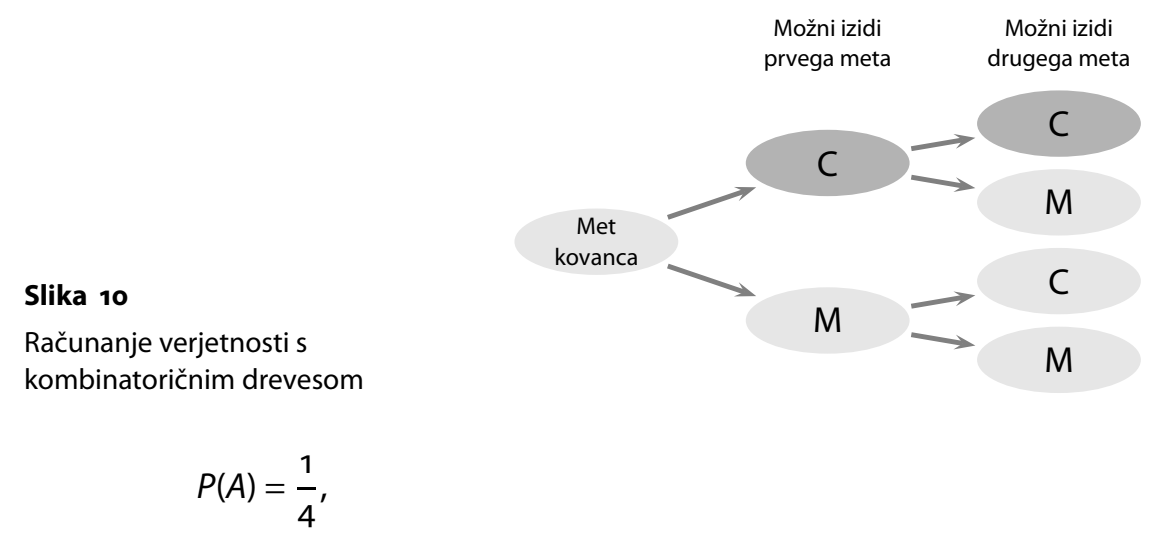

saj imamo štiri možne izide $(C, C),(C, M),(M, C),(M, M)$, od katerih je ugoden en sam (C, C) (slika 10).

4. Statistično pojmovanje verjetnosti: dijaki so se že v osnovni šoli srečali s pojmom statistične definicije verjetnosti. Opazili so, da se z večjim številom poskusov relativne frekvence bližajo določeni vrednosti, ki jo imenujemo verjetnost dogodka. Z ozirom na dejstvo, da se v četrtem letniku, ko se srečajo z verjetnostnim računom, obenem srečujejo s pojmoma limita in osnove infinitezimalnega računa, je mogoče statistično pojmovanje verjetnosti dodatno obogatiti in povezati z matematično analizo. Ponazorimo: če z $n$ označimo število izvedb (ponovitev) poskusa in s $f(n)$ (absolutno) frekvenco, ko se opazuje željeni $\operatorname{dogodek} A$, je verjetnost $P(A)$ enaka:

$$
P(A)=\frac{f(n)}{n} .
$$


Preglednica 2 Primer zapisovanja izidov $v$ tabelo

\begin{tabular}{lllll}
\hline Met št. & Prvi kovanec & Drugi kovanec & $(\mathrm{C}, \mathrm{C})$ & Kumulativno $(\mathrm{C}, \mathrm{C})$ \\
\hline 1 & $\mathrm{C}$ & $\mathrm{M}$ & & \\
2 & $\mathrm{C}$ & $\mathrm{C}$ & $\times$ & 1 \\
3 & $\mathrm{M}$ & $\mathrm{M}$ & & \\
4 & $\mathrm{C}$ & $\mathrm{C}$ & $\times$ & 2 \\
$\ldots$ & $\ldots$ & $\ldots$ & $\ldots$ & $\ldots$ \\
199 & $\mathrm{C}$ & $\mathrm{C}$ & $\times$ & 46 \\
200 & $\mathrm{M}$ & $\mathrm{C}$ & & \\
\hline
\end{tabular}

Zgornji primer meta kovanca in računanja verjetnosti, da dobimo dve cifri, lahko empirično preizkusimo s tem, da dva kovanca hkrati vržemo, denimo, 200-krat, nakar ocenimo verjetnost (preglednica 2), npr.:

$$
P(A)=\frac{46}{200}=0,23=23 \% .
$$

5. Uporablja klasične definicije verjetnosti: cilj učenja verjetnosti na srednji šoli je razumevanje pojma klasična definicija verjetnosti ter uporaba le-te pri reševanju različnih nalog. $Z$ razliko od statistične definicije, ki je a posteriorna definicija (tj. učenec zna oceniti verjetnost potem, ko je opazil pojav), je klasična definicija a priorna. To pomeni, da od dijaka zahteva višje kognitivne procese (Elbehary 2020), ki jih je potrebno razviti postopoma. Kombinatorične spretnosti, ki jih je dijak pridobil v prejšnjih fazah učenja verjetnostnega računa, mu pomagajo posplošiti primere ocene verjetnosti elementarnih dogodkov na težje in zapletenejše kombinatorične situacije.

\section{Sklep}

Verjetnost je matematična veda, ki se ukvarja s slučajnimi dogodki. Z njo se človek srečuje v vsakdanjem življenju; nanjo se opira več znanstvenih in družboslovnih ved. Prav zaradi tega je poučevanje verjetnosti v osnovni in srednji šoli potrebno in pomembno. Po drugi strani so različne raziskave pokazale, da imajo učenci, dijaki in odrasli napačne predstave, ko se poslužujejo verjetnostnega računa. Zato je potrebno poučevanje verjetnosti dodatno izboljšati, razviti in potencirati tako $v$ osnovnošolskem kot srednješolskem izobraževanju. V osnovni šoli se učenci srečujejo s pojmom slučajni dogodki, znajo sprejemati slučajnost in negotovost ter preko poskusov, iger in empirizma pridejo do statistične definicije verjetnosti. Prav na podlagi slednje dijaki srednje šole pridejo do pojma klasična definicija verjetnosti, pri čemer igra po- 
membno vlogo kombinatorika. Poleg tega je verjetnost pomembno poučevati zaradi tega, da učenci pridobijo verjetnostno pismenost (Gal 2005; 2009), ki je v današnji družbi neobhodno potrebna.

\section{Literatura}

Aizikovitsh-Udi, E., in N. Radakovic. 2012. »Teaching Probability by Using Geogebra Dynamic Tool and Implemanting Critical Thinking Skills.« ProcediaSocial and Behavioral Sciences 46:4943-4947.

Amir, G. S., in J. S. Williams. 1999. »Cultural Influences on Children's Probabilistic Thinking.« The Journal of Mathematical Behavior 18 (1): 85-107.

Andrew, L. 2009. »Experimental Probability in Elementary School.» Teaching Statistics 31 (2): 34-36.

Ang, L. H., in M. Shahrill. 2014. »ldentifying Students' Specific Misconceptions in Learning Probability.«International Journal of Probability and Statistics 3 (2): $23-29$.

Aslan, U., in U. Wilensky. 2016. »Old Tricks Revisited: Studying Probabilistic Reasoning through Incorporating Computer Modeling into Piagetian Research." Prispevek predstavljen na 46th annual meeting of the Jean Piaget Society, Chicago, IL, 11. junij.

Astuti, D., L. Anggraeni in F. Setyawan. 2020. "Mathematical Probability: Student's Misconception in Higher Education. "Journal of Physics: Conference Series 1613: 012009. https://doi.org/10.1088/1742-6596/1613/1/012009.

Batanero, C., E. J. Chernoff, J. Engel, H. S. Lee in E. Sánchez. 2016. Research on Teaching and Learning Probability. Cham: Springer.

Batanero, C., in C. Díaz. 2012. »Training School Teachers to Teach Probability: Reflections and Challenges." Chilean Journal of Statistics 3 (1): 3-13.

Batanero, C., M. Henry in B. Parzysz. 2005. »The Nature of Chance and Probability. «V Exploring Probability in School:Challenges for Teaching and Learning, ur. G. A. Jones, 15-37. Boston, MA: Springer.

Batanero, C., in E. Sanchez. 2005. "What is the Nature of High School Students' Conceptions and Misconceptions About Probability? «V Exploring Probability in School: Challenges for Teaching and Learning, ur. G. A. Jones, 241-266. Boston, MA: Springer.

Borovcnik, M. 2016. »Probabilistic Thinking and Probability Literacy in the Context of Risk (Pensamento probabilístico e alfabetização em probabilidade no contexto do risco)." Educação Matemática Pesquisa: Revista do Programa de Estudos Pós-Graduados em Educação Matemática 18 (3): 14911516.

Borovcnik, M., in R. Kapadia. 2009. »Research and Developments in Probability Education. International Electronic Journal of Mathematics Education 4 (3): 111-130.

Borovcnik, M., in R. Peard. 1996. »Probability.«V International Handbook in Ma- 
thematics Education, ur. A. J. Bishop, K. Clements, C. Keitel, J. Kilpatrick in C. Laborde, 239-288. Dordrecht: Kluwer.

Brijlall, D. 2014. »Exploring the Pedagogical Content Knowledge for Teaching Probability in Middle School: A South African Case Study.« International Journal of Educational Sciences 7 (3): 719-726.

Busadee, N., in P. Laosinchai. 2013. »Authentic Problems in High School Probability Lesson: Putting Research into Practice.«Procedia: Social and Behavioral Sciences 93:2043-2047.

Cai, S., E. Liu, Y. Shen, C. Liu, S. Li in Y. Shen. 2020. »Probability Learning in Mathematics Using Augmented Reality: Impact on Student's Learning Gains and Attitudes. « Interactive Learning Environments 28 (5): 560-573.

Candelario-Aplaon, Z. 2017. »Needs Assessment of Senior High School Mathematics Teachers in Teaching Statistics and Probability.« International Forum Journal 20 (2): 143-159.

Carraher, D. W., in A. D. Schliemann. 2002. »ls Everyday Mathematics Truly Relevant to Mathematics Education? «V Everyday and Academic Mathematics in the Classroom, ur. J. Moshkovich in M. Brenner, 238-283. Monographs of the Journal for Research in Mathematics Education 11. Reston, VA: National Council of Teachers of Mathematics.

Clermont, K. M. 2015. „Trial by Traditional Probability, Relative Plausibility, or Belief Function. “Case Western Reserve Law Review 66 (2): 353-391.

- 2020. »The Logic of Uncertainty in Law and Life.« Law, Probability and Risk 19 (2): 181-206.

Conley, Q., R. K. Atkinson, F. Nguyen in B. C. Nelson. 2020. »MantarayAR: Leveraging Augmented Reality to Teach Probability and Sampling."Computers \& Education 153:103895. https://doi.org/10.1016/j.compedu.2020.103895.

Corter, J. E., in D. C. Zahner. 2007. »Use of External Visual Representations in Probability Problem Solving. «Statistics Education Research Journal 6 (1): 22-50.

Cotič, M. 2013. »Learning and Teaching Probability in Basic Education in Slovenia.«V Nastava i učenje: kvalitet vaspitno-obrazovnog procesa, ur. R. Nikolić, 93-102. Užice: Univerzitet u Kragujevcu.

Cotič, M., D. Felda in L. Kozel. 2009. »Razumevanje matematičnega pojma verjetnosti pri otrocih v vrtcu in prvem razredu osnovne šole.« Sodobna pedagogika 60 (3): 96-110.

Danışman, Ş., in D. Tanişli. 2018. »Examination of Mathematics Teachers' Pedagogical Content Knowledge of Probability. « Malaysian Online Journal of Educational Sciences 5 (2): 16-34.

Elbehary, S. 2020. „Discussing the Conditional Probability from a Cognitive Psychological Perspective.«American Journal of Educational Research 8 (7): 491-501.

Fast, G. R. 1997. »Using Analogies to Overcome Student Teachers' Probability Misconceptions." The Journal of Mathematical Behavior 16 (4): 325-344. 
Fischbein, E., in A. Gazit. 1984. »Does the Teaching of Probability Improve Probabilistic Intuitions?« Educational Studies in Mathematics 15 (1): 1-24.

Gal, I. 2005. »Towards 'Probability Literacy' for All Citizens: Building Blocks and Instructional Dilemmas." V Exploring Probability in School: Challenges for Teaching and Learning, ur. G. A. Jones, 39-63. Boston, MA: Springer.

- 2009. "South Africa's Mathematical Literacy and Mathematics Curricula: Is Probability Literacy Given a Fair Chance?« African Journal of Research in Mathematics, Science and Technology Education 13 (1): 50-61.

Gestinv. 2021. »Gestinv 3.0 Archivio interattivo delle prove Invalsi. https://www .gestinv.it/Matematica.aspx.

Girotto, V., L. Fontanari, M. Gonzalez, G. Vallortigara in A. Blaye. 2016. »Young Children Do Not Succeed in Choice Tasks that Imply Evaluating Chances." Cognition 152:32-39.

Gürbüz, R., in O. Birgin. 2012. »The Effect of Computer-Assisted Teaching on Remedying Misconceptions: The Case of the Subject 'Probability.'« Computers \& Education 58 (3): 931-941.

Halpern, N. 1987. »Teaching Probability - Some Legal Applications. «The Mathematics Teacher 80 (2): 150-153.

Hodnik Čadež, T., in M. Škrbec. 2011. »Understanding the Concepts in Probability of Pre-School and Early School Children. Eurasia Journal of Mathematics, Science and Technology Education 7 (4): 263-279.

Jones, G. A., C. W. Langrall, C. A. Thornton in A. T. Mogill. 1997. »A Framework for Assessing and Nurturing Young Children's Thinking in Probability.«Educational Studies in Mathematics 32:101-125.

—. 1999. "Students' Probabilistic Thinking in Instruction. « Journal for Research in Mathematics Education 30 (5): 487-519.

Kahneman, D. 2003. »A Perspective on Judgment and Choice: Mapping Bounded Rationality.« American Psychologist 58 (9): 697-720.

Kahneman, D., in A. Tversky. 1972. »Subjective Probability: A Judgment of Representativeness. " Cognitive Psychology 3 (3): 430-454.

- 1982. "Judgment under Uncertainty: Heuristics and Biases." V Judgment under Uncertainty: Heuristics and Biases, ur. D. Kahneman, P. Slovic in A. Tversky, 3-20. Cambridge: Cambridge University Press.

Kapadia, R., in M. Borovcnik. 1991. »The Educational Perspective. « Chance Encounters: Probability in Education, ur. R. Kapadia in M. Borovcnik, 1-26. Dordrecht: Springer.

Khazanov, L., in L. Prado. 2010. „Correcting Students' Misconceptions about Probability in an Introductory College Statistics Course." Adults Learning Mathematics 5 (1): 23-35.

Konold, C. 1994. »Teaching Probability through Modeling Real Problems.« Mathematics Teacher 87 (4): 232-235.

Koparan, T., in G. K. Yilmaz. 2015. »The Effect of Simulation-Based Learning on 
Prospective Teachers' Inference Skills in Teaching Probability.« Universal Journal of Educational Research 3 (11): 775-786.

Metz, M. L. 2010. »Using GAISE and NCTM Standards as Frameworks for Teaching Probability and Statistics to Pre-Service Elementary and Middle School Mathematics Teachers." Journal of Statistics Education 18 (3). https://doi.org/10.1080/10691898.2010.11889585.

Mezhennaya, N. M., in O. V. Pugachev. 2018. „On the Results of Using Interactive Education Methods in Teaching Probability Theory."Problems of Education in the 21st Century 76 (5): 678-692.

Ministrstvo za šolstvo in šport. 2008. Učni načrt: matematika; gimnazija. Ljubljana: Ministrstvo za šolstvo in šport in Zavod Republike Slovenije za šolstvo.

_. Program osnovna šola: matematika; učni načrt. Ljubljana: Ministrstvo za šolstvo in šport in Zavod Republike Slovenije za šolstvo.

Nikiforidou, Z. 2018. »Probabilistic Thinking and Young Children: Theory and Pedagogy." V Statistics in Early Childhood and Primary Education, ur. A. Leavy, M. Meletiou-Mavrotheris in E. Paparistodemou, 21-34. Singapore: Springer.

_. 2019. »Probabilities and Preschoolers: Do Tangible Versus Virtual Manipulatives, Sample Space, and Repetition Matter?« Early Childhood Education Journal 47 (6): 769-777.

Ottaviani, M. G. 2011. »Insegnare ed apprendere statistica e probabilità a scuola: il problema dell'aggiornamento degli insegnanti.« Periodico di matematiche 3:33-44.

Ottaviani, M. G., S. Mignani in R. Ricci. 2005. »Metodi statistici per la valutazione di abilità e competenze: uno studio di caso che riguarda la matematica." V Atti del XXV Convegno UMI-CIIM »Valutare in Matematica«, 113-114. Siena: Unione Matematica Italiana.

Paul, M., in N. Hlanganipai. 2014. »The Nature of Misconceptions and Cognitive Obstacles Faced by Secondary School Mathematics Students in Understanding Probability: A Case Study of Selected Polokwane Secondary Schools. "Mediterranean Journal of Social Sciences 5 (8): 446-446.

Piaget, J., in B. Inhelder. 2015. The Origin of the Idea of Chance in Children. New York: Psychology.

OECD. 2018a. PISA 2018 Assessment and Analytical Framework. Pariz: OECD. . PISA 2021 Mathemathics Framework (Draft). Pariz: OECD.

Pristovnik, T., P. Peer in T. Hodnik Čadež. 2011. »Reševanje problemov iz verjetnostni ob uporabi e-gradiva v četrtem razredu.« Didactica Slovenica 26 (1-2): 102-119.

Sharma, S. 2015. »Teaching Probability: A Socio-Constructivist Perspective.«Teaching Statistics 37 (3): 78-84.

Sheikh, W. 2019. »An Intuitive, Application-Based, Simulation-Driven Approach 
to Teaching Probability and Random Processes. « The International Journal of Electrical Engineering \& Education. https://doi.org/10.1177/ 0020720919866405.

Strokovni svet Republike Slovenije za splošno izobraževanje. 2007. »Srednje strokovno izobraževanje (SSI): katalog znanja; matematika.« http://eportal .mss.edus.si/msswww/programi2012/programi/Ssi/KZ-IK/KZ_MAT_SSI _383_408.pdf.

Taylor, F. M. 2011. »Why Teach Probability in the Elementary Classroom.« Louisiana Association of Teachers Mathematics Journal 2 (1): 1-10.

Toh, T. L., in C. H. I. U. Queenie. 2020. »Development of Framework with Exemplars Using Real-World Context to Teach Probability. « Learning Science and Mathematics 15 (2): 16-29.

Triliana, T., in E. C. M. Asih. 2019. „Analysis of Students' Errors in Solving Probability Based on Newman's Error Analysis. « Journal of Physics: Conference Series 1211: 012061. https://doi.org/10.1088/1742-6596/1211/1/012061.

Tsakiridou, H., in E. Vavyla. 2015. »Probability Concepts in Primary School.«American Journal of Educational Research 3 (4): 535-540.

Tversky, A., in D. Kahneman. 1974. »Judgment under Uncertainty: Heuristics and Biases." Science 185 (4157): 1124-1131.

—. 1983. »Extensional versus Intuitive Reasoning: The Conjunction Fallacy in Probability Judgment.« Psychological Review 90 (4): 293-315.

Vahey, P., N. Enyedy in B. Gifford. 2000. »Learning Probability through the Use of a Collaborative, Inquiry-Based Simulation Environment. « Journal of Interactive Learning Research 11 (1): 51-84.

Veloo, A., in S. Chairhany. 2013. „Fostering Students' Attitudes and Achievement in Probability Using Teams-Games-Tournaments." Procedia: Social and Behavioral Sciences 93:59-64.

Wang, F., in X. Xu. 2016. „Discussion on the Teaching Method of Probability Theory and Mathematical Statistics. " V Proceedings of the 2016 International Conference on Politics, Economics and Law (ICPEL 2016), 0109-0112. Dordrecht: Atlantis Press.

Zetterqvist, L. 2017. »Applied Problems and Use of Technology in an Aligned Way in Basic Courses in Probability and Statistics for Engineering Students: A Way to Enhance Understanding and Increase Motivation. "Teaching Mathematics and its Applications 36 (2): 108-122.

\section{Teaching and Learning Probabilities in Elementary and High School}

Probability is a mathematical field that aims to quantify uncertainty. Even though probability is present in various situations from everyday life, and is the basis of several sciences, the teaching of probability in primary and secondary schools is still problematic. Researches have shown that adults and 
children can be subjected to biased reasoning when dealing with probabilistic situations. In this paper we present the reasons for teaching probability in primary and secondary schools and the didactical principles that should be applied at both school levels. To this end, we present different theoretical approaches to teaching probability in primary and secondary schools which are further supported by examples of how teachers could implement these techniques in teaching probability at different school levels.

Keywords: probability, mathematics, primary school, secondary school, probability literacy 